\begin{tabular}{|c|l|}
\hline Title & Surface complexation reactions of inorganic anions on hydrotal cite like compounds \\
\hline Author(s) & Morimoto, Kazuy a; A nraku, Sohtaro; Hoshino, Jun; Y oneda, Tetsuro; Sato, Tsutomu \\
\hline Citation & $\begin{array}{l}\text { Journal of Colloid and Interface Science, 384(1), 99-104 } \\
\text { https:/doi.org/10.1016/.jcis.2012.06.072 }\end{array}$ \\
\hline Issue Date & 2012 -10-15 \\
\hline Doc URL & http://hdl.handle.net/2115/50355 \\
\hline Type & article (author version) \\
\hline File Information & JCIS384_1_99-104.pdf \\
\hline
\end{tabular}

Instructions for use 


\section{Surface complexation reactions of inorganic anions on hydrotalcite-like compounds}

Kazuya Morimoto ${ }^{\text {a,* }}$, Sohtaro Anraku ${ }^{\text {b }}$, Jun Hoshino ${ }^{\text {b }}$, Tetsuro Yoneda ${ }^{\mathrm{b}}$, Tsutomu Sato ${ }^{\mathrm{b}}$

${ }^{\mathrm{a}}$ Graduate School of Science and Engineering, Ehime University, 2-5 Bunkyo-cho, Matsuyama 790-8577, Japan

${ }^{\mathrm{b}}$ Graduate School of Engineering, Hokkaido University, Kita 13 Nishi 8, Kita-ku, Sapporo 060-8628, Japan

* Corresponding author. Telephone: +81-89-927-9613. Fax: +81-89-927-9590. E-mail: morimoto.kazuya.mz@ehime-u.ac.jp (K. Morimoto). 


\section{ABSTRACT}

Complexation reactions of environmentally important inorganic anions such as nitrate, chloride, sulfate, arsenate, and phosphate on the surface of hydrotalcite-like compounds (HT) were investigated to understand the role of HT in the immobilization of hazardous anions in an alkaline environment. The effects of surface complexation reactions on the solid state properties of HT were also evaluated to understand their stability. Synthetic HT was used for the adsorption and post-adsorption experiments. The obtained adsorption isotherms showed that the order of selectivity of $\mathrm{HT}$ for anions was $\mathrm{NO}_{3}<\mathrm{Cl}<\mathrm{SO}_{4}<\mathrm{AsO}_{4}<\mathrm{PO}_{4}$. To distinguish the adsorption mechanisms (inner-sphere complexes or outer-sphere complexes) of these anions, zeta potential measurements and infrared absorption spectroscopic analysis were performed. The results indicated that $\mathrm{NO}_{3}$ and $\mathrm{Cl}$ were adsorbed as diffuse ions on the outer surfaces of the $\mathrm{HT}$, while $\mathrm{SO}_{4}$ formed outer-sphere complexes with a strong electrostatic interaction. Moreover, $\mathrm{AsO}_{4}$ and $\mathrm{PO}_{4}$ formed inner-sphere complexes via a ligand substitution reaction on the HT surfaces. And it was suggested that oxyanions with low ionic potential, such as $\mathrm{AsO}_{4}$ and $\mathrm{PO}_{4}$, had a tendency to form inner-sphere complexes with the HT surfaces. The formation of inner-sphere complexes shifted the isoelectric point and the surface charge of the HT. Furthermore, the solubility of the HT was reduced by the inner-sphere complexes with $\mathrm{PO}_{4}$ and $\mathrm{AsO}_{4}$. It was revealed that the formation of inner-sphere complexes on the HT surfaces contributed to the stabilization of the HT, as well as a decrease in the mobility of these anions.

Keywords: Hydrotalcite-like compounds, Layered double hydroxides, Inorganic anions, Adsorption, Surface complexation reactions, Ionic potential, Solubility. 


\section{Introduction}

Hydrotalcite-like compounds (HT), which are also referred to as layered double hydroxides (LDH), are well known as anionic clays due to their anion-exchange properties [1]. The general formula for HT is:

$$
\left[\mathrm{Mg}^{2+}{ }_{1-x} \mathrm{Al}^{3+}{ }_{x}(\mathrm{OH})_{2}\right]\left(A^{n-}\right)_{x / n} \cdot m \mathrm{H}_{2} \mathrm{O}
$$

where $x$ is equal to the $\mathrm{Al} /(\mathrm{Mg}+\mathrm{Al})$ molar fraction and ranges from 0.17 to 0.33 , and $A^{n-}$ is the interlayer anion with a valence of $n[2,3]$. The brucite-like trioctahedral layers have a positive charge due to the isomorphic substitution of $\mathrm{Al}^{3+}$ for $\mathrm{Mg}^{2+}$, and anions are intercalated into the interlayer to maintain electroneutrality. It has been thought that the interlayer anions can be exchanged for other anions with higher selectivity. Miyata [4] represented the order of anion selectivity derived from the selectivity coefficients as follows:

$$
\begin{gathered}
\mathrm{I}^{-}<\mathrm{NO}_{3}^{-}<\mathrm{Br}^{-}<\mathrm{Cl}^{-}<\mathrm{F}^{-}<\mathrm{OH}^{-} \text {for monovalent anions } \\
\mathrm{SO}_{4}{ }^{2-}<\mathrm{CO}_{3}{ }^{2-} \text { for divalent anions }
\end{gathered}
$$

This anion selectivity depends on the diameter of the non-hydrated anion and its valence [4].

Recently HT have attracted considerable attention because of their extremely high anion-exchange capacities of about $3 \mathrm{meq} / \mathrm{g}$ [4,5], which are comparable to organic anion-exchange resins. Therefore, HT have been utilized as adsorbents in the removal of various pollutants from aqueous solutions. The adsorption characteristics of inorganic anions such as borate, nitrate, fluoride, phosphate, sulfate, chromate, arsenate, and selenate, have been investigated (e.g., ref [6,7]). However, the adsorption mechanisms have not been fully elucidated, especially the surface complexation reactions, as pointed out by Goh et al. [7].

The adsorption modes of ions on mineral surfaces are mainly divided into outer-sphere and inner-sphere surface complexes. In general, the chemical interactions in inner-sphere complexes are stronger than those of outer-sphere complexes [8]. These differences in binding strengths 
influence the mobilities of ionic species in the environment. Hence, a distinction between outer-sphere and inner-sphere complexes is significant in evaluating the degree of anion fixation after adsorption onto HT. However, it has been mostly assumed that the adsorption mechanisms of anions onto HT are based on the formation of outer-sphere complexes in the interlayer by anion-exchange reactions.

In this context, this study focused on surface complexation reactions on the HT surfaces in order to examine the adsorption mechanisms of anions onto HT. Environmentally important inorganic anions such as nitrate $\left(\mathrm{NO}_{3}\right)$, chloride $(\mathrm{Cl})$, sulfate $\left(\mathrm{SO}_{4}\right)$, arsenate $\left(\mathrm{AsO}_{4}\right)$, and phosphate $\left(\mathrm{PO}_{4}\right)$ ions were used as the adsorbates in the experiments. To distinguish the inner-sphere complexes from the outer-sphere complexes of these anions, zeta potential measurements and infrared absorption spectroscopic analysis were performed. Furthermore, the effects of complexation reactions on the solid state properties of HT were also evaluated.

\section{Materials and methods}

\subsection{Synthesis of $H T$}

The HT were synthesized with reference to the procedure of previous investigations $[2,3]$. Briefly, $50 \mathrm{~mL}$ of an aqueous solution containing $\mathrm{Mg}\left(\mathrm{NO}_{3}\right)_{2} \cdot 6 \mathrm{H}_{2} \mathrm{O}$ and $\mathrm{Al}\left(\mathrm{NO}_{3}\right)_{3} \cdot 9 \mathrm{H}_{2} \mathrm{O}$, with a $\mathrm{Mg} / \mathrm{Al}$ molar ratio of 3 and a total metal ion concentration of $0.8 \mathrm{~mol} / \mathrm{L}$, was continuously added to $50 \mathrm{~mL}$ of $0.2 \mathrm{~mol} / \mathrm{L} \mathrm{Na} \mathrm{CO}_{3}$ solution in a polypropylene reactor. The solutions were stirred vigorously at room temperature. The $\mathrm{pH}$ was maintained at a constant value of 10 by the simultaneous addition of $2 \mathrm{~mol} / \mathrm{L} \mathrm{NaOH}$ solution during precipitation. The $\mathrm{pH}$ of the suspension was measured with a $\mathrm{pH}$ meter (TOA DKK HM-20P with calibrated $\mathrm{pH}$ glass electrode). The total volume of the resulting suspension was adjusted to $200 \mathrm{~mL}$ by adding distilled water. Then, the suspension was aged hydrotermally using a Teflon lined stainless steel crucible at $150{ }^{\circ} \mathrm{C}$ for 
48 hours in a thermostatic oven. After the hydrothermal treatment, the obtained solid products were collected by centrifugation and washed with distilled water. The washed products were dried for 48 hours using a vacuum freeze drier. In the HT preparation, the use of glassware was completely avoided to prevent contamination with silicate ions.

\subsection{Calcination of $H T$}

Previous studies [2,9] confirmed that the calcinations of HT at $500{ }^{\circ} \mathrm{C}$ will undergo transformation into $\mathrm{Mg}-\mathrm{Al}$ mixed oxides that would revert to the original layered structure in the presence of water and anions through a rehydration reaction. Through this reaction, rehydrated HT with hydroxide ions in the interlayers can be ideally derived. To obtain oxides with mixed $\mathrm{Mg}$-Al, synthesized $\mathrm{HT}$ were calcined in a muffle furnace at $500{ }^{\circ} \mathrm{C}$ for two hours. The calcined HT samples were recovered without grinding and were used in anion adsorption experiments as the precursors of HT.

\subsection{Anion adsorption experiments}

Batch adsorption experiments were carried out for anion adsorption onto HT. Reagents of $\mathrm{NaNO}_{3}, \mathrm{NaCl}, \mathrm{Na}_{2} \mathrm{SO}_{4}, \mathrm{Na}_{2} \mathrm{HAsO}_{4}$, and $\mathrm{Na}_{2} \mathrm{HPO}_{4}$ were used as sources of each adsorbate anion. The adsorption experiments of each anion were tested separately. To minimize the influence of carbon dioxide, de-aerated distilled water was used. Solutions with a constant volume of $40 \mathrm{~mL}$ and having various initial concentrations of anions $(\leq 10 \mathrm{mmol} / \mathrm{L})$ were prepared, and mixed with $40 \mathrm{mg}$ of calcined $\mathrm{HT}$ in $50 \mathrm{~mL}$ polypropylene centrifuge tubes. The suspensions were dispersed in an ultrasonic bath for two minutes, and then placed in a shaker for 24 hours at $25{ }^{\circ} \mathrm{C}$. For $\mathrm{NO}_{3}$ ions adsorption, the adsorption experiments were conducted under light shielding. After adsorption, the equilibrium $\mathrm{pH}$ values of the suspensions were measured with a 
$\mathrm{pH}$ meter. The suspensions were then separated by centrifugation and the supernatant solutions were filtered through a $0.2 \mu \mathrm{m}$ PTFE membrane filter. The obtained filtrate was analyzed for remaining anion and metal ion concentrations. Some colloidal aluminum was maybe contained in the filtrate.

The concentrations of nitrate ions were analyzed by absorption spectrophotometry using a JASCO V-550. The concentrations of chloride ions were analyzed by ion chromatography using a Metrohm 861 Advanced Compact IC. The concentrations of magnesium, aluminum, sulfur, arsenic and phosphorus were analyzed by inductively-coupled plasma atomic emission spectrometry (ICP-AES) using a SHIMADZU ICPE-9000.

\subsection{Characterization of $H T$ samples}

The $\mathrm{Mg} / \mathrm{Al}$ molar ratio of rehydrated HT was determined as follows. Precisely $10.0 \mathrm{mg}$ of rehydrated HT was dissolved in $100 \mathrm{~mL}$ of $1 \mathrm{~mol} / \mathrm{L} \mathrm{HNO}_{3}$. Then the solution was diluted to one-tenth with ultrapure water. The obtained solution was analyzed for magnesium and aluminum concentrations using a SHIMADZU ICPE-9000 (ICP-AES).

Rehydrated HT and anion-adsorbed HT were characterized by powder X-ray diffraction (XRD), attenuated total reflection Fourier-transform infrared (ATR-FTIR), and zeta potential measurements. The XRD profiles of the samples were collected using a Rigaku RINT 2100 powder diffractometer with $\mathrm{Cu} K \alpha$ radiation $(\lambda=0.15406 \mathrm{~nm})$ at $30 \mathrm{kV}$ and $20 \mathrm{~mA}$ in the 2 to $70^{\circ}$ range, with a scanning rate of $1 \% \mathrm{~min}$. The ATR-FTIR spectra of rehydrated HT, anion-adsorbed HT powder, and solutions containing each anion, were recorded using a JASCO FT/IR-6200 spectrometer with a diamond crystal from 400 to $4000 \mathrm{~cm}^{-1}$. The zeta potential measurements of the HT suspensions with adsorbed anions were carried out using a MALVERN Zetasizer NanoZS90 at $25{ }^{\circ} \mathrm{C}$. The concentrations of suspended solids were adjusted to $1.0 \mathrm{~g} / \mathrm{L}$. 
Concurrently, the $\mathrm{pH}$ values of the suspensions were also determined, and the $\mathrm{pH}$ was changed using an autotitrator (MALVERN MPT-2) by the addition of $0.1 \mathrm{~mol} / \mathrm{L} \mathrm{HNO}_{3}$ solution.

\subsection{Speciation and activity analysis}

The speciation, activity and saturation calculations were determined by using PHREEQC code [10], and the thermodynamic database THERMODDEM [11] was used in the calculations. The extended Debye-Hückel equation [8] was used for calculating the activity coefficients.

\section{Results and discussion}

\subsection{Adsorption isotherms}

The adsorption isotherms of inorganic anions $\left(\mathrm{NO}_{3}, \mathrm{Cl}, \mathrm{SO}_{4}, \mathrm{AsO}_{4}\right.$, and $\left.\mathrm{PO}_{4}\right)$ onto HT are shown in Fig. 1. The amounts of adsorbed anions are expressed in mmol/g-calcined HT, which does not reflect the equivalent of anionic valence. The equilibrium $\mathrm{pH}$ rose with increasing amounts of anion adsorption, in every anion system. This indicates that hydroxide ions in the HT interlayer were released into the bulk solution by adsorption of the other anions. The results in Fig. 1 showed that the order of anion selectivity of $\mathrm{HT}$ is $\mathrm{NO}_{3}<\mathrm{Cl}<\mathrm{SO}_{4}<<\mathrm{AsO}_{4}<\mathrm{PO}_{4}$. Hence, the resulting orders of selectivity based on the mole amounts are consistent with the results of Miyata [4]. If the anions are intercalated into the HT interlayers with the same chemical species as the dissolved anions in the bulk solution ( $\mathrm{pH} 10.6$ to $\mathrm{pH} 11.4$ ), $\mathrm{NO}_{3}$ and $\mathrm{Cl}$ display an exchange efficiency of only about 15 percent of the theoretical anion-exchange capacity of HT ( $6.10 \mathrm{meq} / \mathrm{g}$-calcined HT). Therefore, the rest should be compensated by hydroxide ions. And sorbed $\mathrm{SO}_{4}$ amounts for 30 percent of the total anion exchange capacity. In particular, $\mathrm{AsO}_{4}$ and $\mathrm{PO}_{4}$ ions showed great affinity for $\mathrm{HT}$. 


\subsection{Characteristics of rehydrated HT and HT with adsorbed anions}

Rehydrated HT represents the fully-hydrated $\mathrm{Mg}$-Al mixed oxides in anion-free distilled water. The $\mathrm{Mg} / \mathrm{Al}$ molar ratio of rehydrated $\mathrm{HT}$ was determined to be 3.0 by ICP-AES analysis. This resulting ratio corresponds exactly to the composition of the mixed metal solution prepared in the HT synthesis process.

The XRD patterns of rehydrated HT and HT with adsorbed anions are shown in Fig. 2. The XRD pattern of rehydrated HT showed a clear layered structure, and there were no crystalline by-products. The measured $d_{003}$ spacing was $0.770 \mathrm{~nm}$, which contains hydroxide ions in the interlayer. Rehydrated HT was completely restored to the original layered structure within 24 hours in distilled water. The $d_{003}$ values of $\mathrm{HT}$ with adsorbed $\mathrm{NO}_{3}\left(\mathrm{HT}-\mathrm{NO}_{3}\right), \mathrm{Cl}(\mathrm{HT}-\mathrm{Cl}), \mathrm{SO}_{4}$ $\left(\mathrm{HT}-\mathrm{SO}_{4}\right), \mathrm{AsO}_{4}\left(\mathrm{HT}-\mathrm{AsO}_{4}\right)$, and $\mathrm{PO}_{4}\left(\mathrm{HT}-\mathrm{PO}_{4}\right)$, were $0.776,0.782,0.798,0.774$, and $0.768 \mathrm{~nm}$, respectively. The $d_{003}$ spacing is equivalent to the thickness of the unit layers. Since the thickness of brucite-like layers is $0.477 \mathrm{~nm}$ [12], the interlayer spacing can be calculated as 0.293, 0.299, 0.305, 0.321, 0.297, and $0.291 \mathrm{~nm}$, respectively, for rehydrated HT, HT-NO HT-Cl, HT-SO ${ }_{4}, \mathrm{HT}-\mathrm{AsO}_{4}$, and HT-PO ${ }_{4}$. On the other hand, the ionic diameters of $\mathrm{NO}_{3}{ }^{-}, \mathrm{Cl}^{-}$, $\mathrm{SO}_{4}{ }^{2-}, \mathrm{AsO}_{4}{ }^{3-}, \mathrm{HPO}_{4}{ }^{2-}$, and $\mathrm{OH}^{-}$are $0.358,0.362,0.480,0.496,0.476$, and $0.266 \mathrm{~nm}$, respectively [13]. It can clearly be seen that $\mathrm{NO}_{3}$ and $\mathrm{Cl}$ ions have very similar ionic diameters and charge densities, and the interlayer distances of $\mathrm{HT}-\mathrm{NO}_{3}$ and $\mathrm{HT}-\mathrm{Cl}$ were also similar. However, these interlayer distances were smaller than their anionic diameters, which is attributable to the surplus $\mathrm{OH}^{-}$ions still remaining in the $\mathrm{HT}$ interlayers. In contrast, the diameters of $\mathrm{SO}_{4}$ ions are relatively large, and the interlayer distance of $\mathrm{HT}_{-} \mathrm{SO}_{4}$ was larger in comparison to $\mathrm{HT}-\mathrm{NO}_{3}$ and $\mathrm{HT}-\mathrm{Cl}$. In the case of $\mathrm{HT}-\mathrm{AsO}_{4}$ and $\mathrm{HT}-\mathrm{PO}_{4}$, their interlayer spacing were very similar to those of $\mathrm{HT}-\mathrm{NO}_{3}$ and $\mathrm{HT}-\mathrm{Cl}$ even though $\mathrm{AsO}_{4}$ and $\mathrm{PO}_{4}$ ions have diameters and charge densities similar to $\mathrm{SO}_{4}$ ions. This result suggests that $\mathrm{AsO}_{4}$ and $\mathrm{PO}_{4}$ ions 
could interact strongly with the brucite-like sheets in the HT interlayers. The study of Gillman et al. [14] also observed the changes in the $d_{003}$ spacing of HT in relation to the adsorbed amount of $\mathrm{SO}_{4}$ and $\mathrm{PO}_{4}$ ions, and confirmed that the $d_{003}$ spacing of $\mathrm{HT}$ with adsorbed $\mathrm{PO}_{4}$ varied only slightly with increasing adsorbed amounts, when compared to $\mathrm{SO}_{4}$ adsorption, which increased significantly. This is in agreement with the current results of $\mathrm{AsO}_{4}$ and $\mathrm{PO}_{4}$ adsorption by HT, wherein these ions exhibit different adsorption behavior compared to $\mathrm{SO}_{4}$, though they have charge densities similar to $\mathrm{SO}_{4}$ ions.

\subsection{Adsorption mechanisms of anions on HT}

Fig. 3 shows the zeta potential of HT samples with adsorbed anions. The zeta potential of rehydrated HT developed a positive charge of approximately $+33 \mathrm{mV}$ at $\mathrm{pH} 10.6$, which is attributable to the permanent structural charge and the protonation reactions of surface hydroxyl groups. Moreover, Han et al. [15] also reported that the isoelectric point $\left(\mathrm{pH}_{\mathrm{IEP}}\right)$ of HT is greater than or equal to 12 . For $\mathrm{HT}-\mathrm{NO}_{3}$ and $\mathrm{HT}-\mathrm{Cl}$, only slight shifts in the zeta potential within the $\mathrm{pH}$ range from 10.7 to 11.1 were observed. However, the zeta potential of $\mathrm{HT}^{-\mathrm{SO}_{4}}$ decreased significantly in the $\mathrm{pH}$ range, from 10.8 to 11.4 , when the adsorbed amount increased. The zeta potential of HT samples nearly saturated with $\mathrm{SO}_{4}$ was around $0 \mathrm{mV}$. The zeta potentials of HT- $\mathrm{AsO}_{4}$ and $\mathrm{HT}-\mathrm{PO}_{4}$ also decreased in the $\mathrm{pH}$ range, from 10.6 to 11.4 , with increases in adsorbed amounts, but the zeta potentials dropped to negative values compared to $\mathrm{HT}_{-} \mathrm{SO}_{4}$. These results indicate that $\mathrm{AsO}_{4}$ and $\mathrm{PO}_{4}$ ions were strongly attached on the HT surfaces in addition to the charge balance.

The study of Chatelet et al. [5] also conducted zeta potential measurements of HT samples dispersed in electrolyte solutions containing various anions such as $\mathrm{Cl}^{-}, \mathrm{SO}_{4}{ }^{2-}, \mathrm{CO}_{3}{ }^{2-}$, and $\mathrm{CrO}_{4}{ }^{2-}$, and concluded that the zeta potential of the $\mathrm{HT}$ only dropped significantly when $\mathrm{SO}_{4}{ }^{2-}, \mathrm{CO}_{3}{ }^{2-}$, 
and $\mathrm{CrO}_{4}{ }^{2-}$ were used. Their results suggest that $\mathrm{SO}_{4}{ }^{2-}, \mathrm{CO}_{3}{ }^{2-}$, and $\mathrm{CrO}_{4}{ }^{2-}$ were adsorbed strongly on the outer surfaces of the HT. The findings of Lagaly et al. [16] also confirmed the significant decreases in the zeta potential of HT dispersed in $\mathrm{HPO}_{4}{ }^{2-}$ electrolyte solution. However, these studies made no reference to the adsorption mechanisms of anions.

It is generally assumed that the zeta potential corresponds to the electrostatic potential at the shear or slipping plane, which is the boundary between the liquid adhering to the solid surfaces and the mobile liquid, and is established by means of electrophoretic mobility measurements. This shear or slipping plane is located slightly outside of the $d$-plane, which is the plane bordering the diffusion layer in the triple-layer model by Hayes et al. [17]. Thus, the results suggest that $\mathrm{NO}_{3}$ and $\mathrm{Cl}$ ions were distributed in the diffusion layer as diffuse ions on the HT outer surfaces, while $\mathrm{SO}_{4}, \mathrm{AsO}_{4}$, and $\mathrm{PO}_{4}$ ions formed either outer-sphere complexes with a strong electrostatic interaction or inner-sphere complexes within the shear plane of the HT.

To investigate further the adsorption mechanisms of $\mathrm{SO}_{4}, \mathrm{AsO}_{4}$, and $\mathrm{PO}_{4}$ ions on $\mathrm{HT}$, infrared absorption spectra measurements were also performed. The infrared absorption spectrum of HT-SO ${ }_{4}$, measured by an attenuated total reflection Fourier-transform infrared (ATR-FTIR) method, is shown in Fig. 4A. The spectrum of the $0.5 \mathrm{~mol} / \mathrm{L} \mathrm{Na}_{2} \mathrm{SO}_{4}$ solution adjusted to $\mathrm{pH} 10$ was also conducted for comparison. The infrared spectrum of the $\mathrm{Na}_{2} \mathrm{SO}_{4}$ solution showed an absorption band at around $1100 \mathrm{~cm}^{-1}$, which corresponds to the antisymmetric stretching vibrations $\left(v_{3}\right)$ of dissolved $\mathrm{SO}_{4}{ }^{2-}[18]$. The spectrum of $\mathrm{HT}-\mathrm{SO}_{4}$ was also similar to the spectrum of the $\mathrm{Na}_{2} \mathrm{SO}_{4}$ solution, and only a slight shift to a higher wavenumber was detected. However, it has been reported that when $\mathrm{SO}_{4}$ ions are in direct combination with metal atoms, the symmetric vibrations $\left(v_{1}\right)$ of $\mathrm{SO}_{4}$ exhibit infrared activity at around $975 \mathrm{~cm}^{-1}$, and the antisymmetric stretching vibrations $\left(v_{3}\right)$ of $\mathrm{SO}_{4}$ are divided into two or more peaks [19-21]. Hence, the results suggest that $\mathrm{SO}_{4}$ ions were mainly adsorbed as outer-sphere complexes on the 
$\mathrm{HT}$, and the changes in the zeta potential clearly show that $\mathrm{SO}_{4}$ ions were adsorbed with a much stronger electrostatic interaction than $\mathrm{NO}_{3}$ or $\mathrm{Cl}$ ions. The strong retention of $\mathrm{SO}_{4}$ may cause the slight shift in the infrared spectrum of $\mathrm{HT}-\mathrm{SO}_{4}$.

The infrared absorption spectrum of $\mathrm{HT}-\mathrm{AsO}_{4}$ and the $0.5 \mathrm{~mol} / \mathrm{L} \mathrm{Na}_{2} \mathrm{HAsO}_{4}$ solution adjusted to $\mathrm{pH} 10$ are shown in Fig. 4B. The absorption band around $860 \mathrm{~cm}^{-1}$ in the spectrum of the $\mathrm{Na}_{2} \mathrm{HAsO}_{4}$ solution corresponds to the antisymmetric stretching vibrations $\left(v_{3}\right)$ of dissolved $\mathrm{HAsO}_{4}{ }^{2-}[22,23]$. The spectrum of $\mathrm{HT}-\mathrm{AsO}_{4}$ showed a broad peak around $810 \mathrm{~cm}^{-1}$, which is similar to $\mathrm{AsO}_{4}$ ions forming inner-sphere complexes under alkaline conditions on ferric or titanium oxide surfaces $[23,24]$.

The infrared absorption spectrum of $\mathrm{HT}-\mathrm{PO}_{4}$ is shown in Fig. $4 \mathrm{C}$, together with the spectrum of the $0.5 \mathrm{~mol} / \mathrm{L} \mathrm{Na}_{2} \mathrm{HPO}_{4}$ solution adjusted to $\mathrm{pH} 10$. The absorption bands around $990 \mathrm{~cm}^{-1}$ and $1077 \mathrm{~cm}^{-1}$, shown by the $\mathrm{Na}_{2} \mathrm{HPO}_{4}$ solution, correspond to antisymmetric stretching vibrations $\left(v_{3}\right)$ of dissolved $\mathrm{HPO}_{4}{ }^{2-}[21,25]$. The spectrum of $\mathrm{HT}-\mathrm{PO}_{4}$ showed a characteristic absorption peak at $1032 \mathrm{~cm}^{-1}$ and a shoulder around $1090 \mathrm{~cm}^{-1}$, which is completely different from the spectrum of the $\mathrm{Na}_{2} \mathrm{HPO}_{4}$ solution. This observation agrees with previous findings that when $\mathrm{PO}_{4}$ ions form inner-sphere complexes under alkaline conditions on ferric hydroxide surfaces, the characteristic bands of antisymmetric stretching vibrations $\left(v_{3}\right)$ of $\mathrm{PO}_{4}$ appear at $1044 \mathrm{~cm}^{-1}$ and $1089-1096 \mathrm{~cm}^{-1}[25-27]$.

These results clearly indicate that the adsorbed $\mathrm{AsO}_{4}$ and $\mathrm{PO}_{4}$ on the HT were of a different form than the dissolved ions, and were forming inner-sphere complexes directly with the metals ( $\mathrm{Mg}$ or $\mathrm{Al}$ ) via ligand-exchange reactions with hydroxyl groups on the HT surfaces. The observed changes in the zeta potential may reflect the adsorption reactions of anions on the HT outer surfaces, while the infrared spectra reflect the adsorption reactions of anions on the whole of the HT solid phase. Therefore, the formation of inner-sphere complexes in the $\mathrm{AsO}_{4}$ and $\mathrm{PO}_{4}$ 
systems occurred both on the HT outer surfaces and on interlayer sites. The smaller interlayer distances and the broad diffraction patterns of HT-AsO $\mathrm{A}_{4}$ and $\mathrm{HT}-\mathrm{PO}_{4}$, as estimated by the XRD analysis may reflect the above reactions in the interlayer. Such specific adsorption of $\mathrm{AsO}_{4}$ and $\mathrm{PO}_{4}$ ions was also reported in other minerals $[28,29]$.

\subsection{Adsorption behaviors and basic properties of inorganic anions}

The anion adsorption mechanisms established in this study indicate significant differences in the chemical bonding strength of each anion with HT. These differences in their adsorption mechanisms greatly influence the adsorption stability and mobility of anions. Moreover, the different adsorption mechanisms also affect the anion selectivity of HT, and the order becomes diffuse ions $\left(\mathrm{NO}_{3}\right.$ and $\left.\mathrm{Cl}\right)<$ outer-sphere complexes $\left(\mathrm{SO}_{4}\right)<$ inner-sphere complexes $\left(\mathrm{AsO}_{4}\right.$ and $\mathrm{PO}_{4}$ ). Miyata [4] represented an order of anion selectivity which is derived from the Gaines-Thomas equilibrium constant for HT, and concluded that the anion selectivity of HT depends on the anionic size and valence. However, $\mathrm{SO}_{4}$ showed different adsorption affinity compared to $\mathrm{AsO}_{4}$ or $\mathrm{PO}_{4}$, even though they have a similar anionic size and valence. Thus, the anionic size and valence are not the only critical factors in determining the adsorption properties of anions on HT.

The relative affinities of anions on HT are strongly associated with their adsorption modes and surface complexation reactions. Particularly in mononuclear oxyacids, the inherent chemical properties of the central elements, such as the ionic potential (IP) $[8,30]$, also contribute to the surface complexation reaction. The IP is expressed as the ratio of the oxidation number to the ionic radius of the central element. The IP values of $\mathrm{N}, \mathrm{S}, \mathrm{P}$, and As were estimated as 38.5, 20.7, 13.2, and 10.9 respectively. Oxyanions with a high IP, such as $\mathrm{NO}_{3}$ and $\mathrm{SO}_{4}$, cause deprotonation reactions, and tend to be present as oxyanions. In contrast, $\mathrm{AsO}_{4}$ and 
$\mathrm{PO}_{4}$ have a low IP, and have a tendency to form inner-sphere complexes with metal atoms on mineral surfaces. Therefore, oxyanions with a low IP, such as molybdate, tungstate, borate, and silicate ions, are expected to have a similar adsorption behavior to $\mathrm{AsO}_{4}$ and $\mathrm{PO}_{4}$. Furthermore, if the complexation reactions of inorganic anions are scrutinized in detail, they may be employed as a qualitative index, in order to predict the adsorption mechanisms of organic anions whose behavior is greatly influenced by the properties of functional groups.

\subsection{Effects of surface complexation on HT properties}

To evaluate the effects of surface complexation reactions of anions on HT's physicochemical properties, isoelectric point $\left(\mathrm{pH}_{\mathrm{IEP}}\right)$ measurements were carried out. The $\mathrm{pH}_{\text {IEP }}$ is a value peculiar to a mineral, and is an important physicochemical indicator of the mineral's surface properties. The $\mathrm{pH}_{\mathrm{IEP}}$ corresponds to a $\mathrm{pH}$ value when the zeta potential is $0 \mathrm{mV}$, and can be obtained by zeta potential measurements with varying $\mathrm{pH}$. The values of the zeta potentials of HT with different anions, as a function of $\mathrm{pH}$ conditions, are shown in Fig. 5. With decreases in $\mathrm{pH}, \mathrm{pH}$ buffering effects may be caused both by releases of interlayer hydroxide ions and by slight dissolutions of the HT itself.

The changes in the zeta potential of rehydrated HT, in the $\mathrm{pH}$ range from 3.9 to 10.5 , were small and varied only from $+33 \mathrm{mV}$ to $+40 \mathrm{mV}$. In the case of $\mathrm{HT}_{-} \mathrm{NO}_{3}$ and $\mathrm{HT}-\mathrm{Cl}$, the zeta potentials were almost the same as that of rehydrated $\mathrm{HT}$, and their corresponding $\mathrm{pH}_{\mathrm{IEP}}$ values were above 11. Since $\mathrm{NO}_{3}$ and $\mathrm{Cl}$ ions were adsorbed on the HT outer surfaces as diffuse ions, these ions have no effect on the zeta potential and the $\mathrm{pH}_{\mathrm{IEP}}$.

On the other hand, the zeta potential of $\mathrm{HT}-\mathrm{SO}_{4}$ is much lower than that of rehydrated HT. This difference may be caused by the strong outer-sphere complexation of $\mathrm{SO}_{4}$ ions inside the $d$-plane. However, it can be expected that the adsorption of $\mathrm{SO}_{4}$ ions on the $\mathrm{HT}$ surfaces was 
owing solely to the maintenance of the electrostastic balance, as it was observed that its zeta potential was almost equal to $0 \mathrm{mV}$ at $\mathrm{pH} 3.5$ to 11.0 .

In the case of the $\mathrm{HT}-\mathrm{AsO}_{4}$ and $\mathrm{HT}-\mathrm{PO}_{4}$ samples, the zeta potentials gradually increase with decreasing $\mathrm{pH}$, from $-30 \mathrm{mV}$ at $\mathrm{pH} 11$ to $0 \mathrm{mV}$ around $\mathrm{pH}$ 5.0. The gradual change in the zeta potential with decreasing $\mathrm{pH}$ might be caused by a decrease in the valences of the adsorbed anion on the HT. The $\mathrm{pH}_{\mathrm{IEP}}$ of both $\mathrm{HT}-\mathrm{AsO}_{4}$ and $\mathrm{HT}-\mathrm{PO}_{4}$ was about 5.0, which differs widely from that of rehydrated HT. Such shifts in the $\mathrm{pH}_{\mathrm{IEP}}$ caused by the specific adsorption of anions were also reported for goethite [31] and allophone [32]. This reaction can cause variations in the intrinsic $\mathrm{pH}_{\mathrm{IEP}}$ for each mineral. Moreover, the drastic fall in the $\mathrm{pH}_{\mathrm{IEP}}$ by anion adsorption on HT may be expected to change the resistance to dissolution reactions of HT, especially under acidic conditions.

To study the influence of inner-sphere complexes on the solubility of HT, the solubility changes of HT with specific adsorbed anions were analyzed. The dissolution reaction of rehydrated $\mathrm{HT}(\mathrm{Mg} / \mathrm{Al}=3)$ synthesized in this experiment may be expressed as $\mathrm{Mg}_{3} \mathrm{Al}(\mathrm{OH})_{9}+$ $9 \mathrm{H}^{+} \rightarrow 3 \mathrm{Mg}^{2+}+\mathrm{Al}^{3+}+9 \mathrm{H}_{2} \mathrm{O}$, and the solubility product $\left(\mathrm{K}_{\mathrm{sp}}\right)$ in the above reaction is $\mathrm{K}_{\mathrm{sp}}=$ $\left(\mathrm{a}_{\mathrm{Mg} 2+}\right)^{3}\left(\mathrm{a}_{\mathrm{Al} 3+}\right) /\left(\mathrm{a}_{\mathrm{H}+}\right)^{9}$. Since the data of the solubility product of HT with $\mathrm{Mg} / \mathrm{Al}=3$ is not available, the IAP (actual ion activity products of the solution) of rehydrated HT was calculated based on the solution composition data at the adsorption equilibrium after 24 hours.

Changes in the IAP of rehydrated $\mathrm{HT}\left(\mathrm{IAP}_{\mathrm{HT}}\right)$, as a function of the amount of adsorbed anions, are shown in Fig. 6. The $\log \left(\mathrm{IAP}_{\mathrm{HT}}\right)$ calculated from the solution composition of anion unfilled sample was 60.5 . However, the $\log \left(\mathrm{IAP}_{\mathrm{HT}}\right)$ of anion added samples varied from 57.8 to 59.6 , and was almost one order of magnitude less than that of the anion unfilled sample. This change was especially large in the case of the $\mathrm{PO}_{4}$ systems. The IAP is an activity product, and $\mathrm{a}_{\mathrm{H}+}$ is present as a chemical species in the $\mathrm{IAP}_{\mathrm{HT}}$. Based on the above equation of the solubility 
products, the ionic strength and $\mathrm{pH}$ are functions of the $\mathrm{IAP}_{\mathrm{HT}}$. Hence, if the $\mathrm{pH}$ increases, $\left(\mathrm{a}_{\mathrm{Mg} 2+}\right)^{3}\left(\mathrm{a}_{\mathrm{Al} 3+}\right)$ decreases. However, the value of the $\mathrm{IAP}_{\mathrm{HT}}$ itself would ideally be constant in every system when anions were added. The decrease in the IAP $_{\mathrm{HT}}$ in the samples with added anions indicates that the solubility of the $\mathrm{HT}$ decreased, even if the $\mathrm{IAP}_{\mathrm{HT}}$ accounts for the differences between the ionic strengths and the $\mathrm{pH}$. This suggests that adsorption reactions with small amounts of $\mathrm{AsO}_{4}$ or $\mathrm{PO}_{4}$ ions can induce a notable decrease in the solubility of HT. This factor may relate to the modification of the HT surfaces caused by the formation of inner-sphere complexes, as established by the zeta potential measurements. It is also known that in iron minerals, the stability of the mineral itself will change depending on the kind of adsorbed ion. Fukushi et al. [33] investigated the adsorption of $\mathrm{AsO}_{4}$ ions on schwertmannite, and concluded that the solubility of schwertmannite was reduced as a result of the reactions due to solid solution formation.

This study confirmed that the formation of inner-sphere complexes on the HT surfaces contributes to the stabilization of HT, and to a decrease in the mobility of anions. It is also noteworthy that the stability of the mineral itself varies accordingly to the kind of adsorbed anion. Hence, it must be stressed that carefully examining the adsorption mechanisms of ions on mineral surfaces is very important, not only in the prediction of the mobility of anions, but also in long-term stability assessments of potential changes in, and the stability of, the mineral. It has recently been noted that there are many environmental issues related to the behavior of harmful anions, especially in the disposal environments of wastes that lead to alkaline conditions. For example, in the disposal or secondary use of steel slag and fly ash, there are growing concerns about the elution of anions such as borate, arsenate, chromate, vanadate, molybdate, and selenate (e.g., ref [34,35]). Consequently, an effective and inexpensive adsorbent for harmful anions has been required in those alkaline disposal sites. In the actual use of a given adsorbent, 
more attention should be paid to its competitive adsorption properties and the post-adsorption stability of the targeted ion. Although it is expected that HT will work well in the immobilization of such hazardous anions, it is not enough to attempt to solve these problems fundamentally based on previous research, which only focused on the adsorbed amounts of various anions on HT in systems independent of each other. The important distinction between outer-sphere and inner-sphere complexes on HT has never even been investigated in many previous studies. And according to the suggestions of previous studies, there is a fear that carbonate ions will compete with the other targeted anion in the use of HT in a natural environment. However, carbonate ions with a high IP are expected to be released when they compete with other anions with a tendency to form inner-sphere complexes, as described in this study. Furthermore, this study confirms the more stable retention of the hazardous oxyanions with a low IP. Thus the findings from this study could provide a new assessment strategy for applications of HT in light of the environmental concerns above.

\section{Conclusions}

The results of adsorption experiments showed that the order of selectivity of HT for anions during adsorption was $\mathrm{NO}_{3}<\mathrm{Cl}<\mathrm{SO}_{4}<\mathrm{AsO}_{4}<\mathrm{PO}_{4}$. The results of zeta potential measurements and infrared absorption spectroscopic analysis indicated that $\mathrm{NO}_{3}$ and $\mathrm{Cl}$ ions were adsorbed as diffuse ions on the outer surfaces of $\mathrm{HT}$, while $\mathrm{SO}_{4}$ formed outer-sphere complexes with a strong electrostatic interaction. Moreover, $\mathrm{AsO}_{4}$ and $\mathrm{PO}_{4}$ formed inner-sphere complexes via a ligand-substitution reaction on the HT surfaces. The adsorption mode of anions on HT should be determined by chemical properties inherent in the elements; oxyanions with a low IP have a tendency to form inner-sphere complexes with the HT surfaces. The formation of inner-sphere complexes shifted the $\mathrm{pH}_{\mathrm{IEP}}$ and the surface charge of the HT. Furthermore, the 
solubility of the $\mathrm{HT}$ was reduced by the inner-sphere complexes with $\mathrm{PO}_{4}$ and $\mathrm{AsO}_{4}$. It was revealed that the formation of inner-sphere complexes on the HT surfaces contributed to the stabilization of the HT, and to a decrease in the mobility of these anions.

\section{Acknowledgements}

This study was partially supported by the 21st century COE (Center of Excellence) program of Hokkaido University. The authors extend heartfelt gratitude to Dr. Shuji Tamamura (Horonobe RISE), Dr. Chelo S. Pascua (University of the Philippines), Dr. Kenji Tamura (NIMS), and Dr. Hirohisa Yamada (NIMS) for their valuable comments and suggestions. The authors are grateful to Prof. Naoki Hiroyoshi (Hokkaido University) for the use of the ATR-IR spectrometer. The authors also want to express special thanks to Dr. Nicolas Marty (BRGM) for help in calculations with PHREEQC, and Prof. Torkil D. Christensen (Hokusei Gakuen University) and Dr. Einstine M. Opiso (Central Mindanao University) for help with the English and discussions. 


\section{References}

[1] X. Duan, D.G. Evans, Layered Double Hydroxides, Springer-Verlag, Berlin, 2005.

[2] S. Miyata, Clay Clay Min. 28 (1980) 50.

[3] W.T. Reichle, Solid State Ion. 22 (1986) 135.

[4] S. Miyata, Clay Clay Min. 31 (1983) 305.

[5] L. Chatelet, J.Y. Bottero, J. Yvon, A. Bouchelaghem, Colloid Surf. A-Physicochem. Eng. Asp. 111 (1996) 167.

[6] L. Lv, J. He, M. Wei, D.G. Evans, Z.L. Zhou, Water Res. 41 (2007) 1534.

[7] K.H. Goh, T.T. Lim, Z. Dong, Water Res. 42 (2008) 1343.

[8] D. Langmuir, Aqueous Environmental Geochemistry, Prentice Hall, New Jersey, 1997.

[9] T. Hibino, Y. Yamashita, K. Kosuge, A. Tsunashima, Clay Clay Min. 43 (1995) 427.

[10] D.L. Parkhurst, C.A.J. Appelo, Water-Resources Investigations Report 99-4259, U. S. Department of the Interior, Colorado, 1999.

[11] P. Blanc, A. Lassin, P. Piantone, C. Nowak, Thermoddem a Database Devoted to Waste Minerals, 2008. Available at http://thermoddem.brgm.fr.

[12] S. Miyata, Clay Clay Min. 23 (1975) 369.

[13] Y. Marcus, Biophys. Chem. 51 (1994) 111.

[14] G.P. Gillman, M.A. Noble, M.D. Raven, Appl. Clay Sci. 38 (2008) 179.

[15] S.H. Han, W.G. Hou, C.G. Zhang, D.J. Sun, X.R. Huang, G.T. Wang, J. Chem. Soc.-Faraday Trans. 94 (1998) 915.

[16] G. Lagaly, O. Mecking, D. Penner, Colloid Polym. Sci. 279 (2001) 1090.

[17] K.F. Hayes, G. Redden, W. Ela, J.O. Leckie, J. Colloid Interface Sci. 142 (1991) 448.

[18] S.J. Hug, J. Colloid Interface Sci. 188 (1997) 415.

[19] D. Peak, R.G. Ford, D.L. Sparks, J. Colloid Interface Sci. 218 (1999) 289. 
[20] H. Wijnja, C.P. Schulthess, J. Colloid Interface Sci. 229 (2000) 286.

[21] G. Lefevre, Adv. Colloid Interface Sci. 107 (2004) 109.

[22] S.C.B. Myneni, S.J. Traina, G.A. Waychunas, T.J. Logan, Geochim. Cosmochim. Acta 62 (1998) 3285.

[23] M. Pena, X.G. Meng, G.P. Korfiatis, C.Y. Jing, Environ. Sci. Technol. 40 (2006) 1257.

[24] J.B. Harrison, V.E. Berkheiser, Clay Clay Min. 30 (1982) 97.

[25] M.I. Tejedor-Tejedor, M.A. Anderson, Langmuir 6 (1990) 602.

[26] C. Luengo, M. Brigante, J. Antelo, M. Avena, J. Colloid Interface Sci. 300 (2006) 511.

[27] E.J. Elzinga, D.L. Sparks, J. Colloid Interface Sci. 308 (2007) 53.

[28] R.L. Parfitt, Adv. Agron. 30 (1978) 1.

[29] K. Fukushi, D.A. Sverjensky, Geochim. Cosmochim. Acta 71 (2007) 3717.

[30] G.H. Cartledge, J. Am. Chem. Soc. 50 (1928) 2855.

[31] D.D. Hansmann, M.A. Anderson, Environ. Sci. Technol. 19 (1985) 544.

[32] C.M. Su, D.L. Suarez, Environ. Sci. Technol. 29 (1995) 302.

[33] K. Fukushi, T. Sato, N. Yanase, Environ. Sci. Technol. 37 (2003) 3581.

[34] A. Iwashita, Y. Sakaguchi, T. Nakajima, H. Takanashi, A. Ohki, S. Kambara, Fuel 84 (2005) 479.

[35] G. Cornelis, C.A. Johnson, T. Van Gerven, C. Vandecasteele, Appl. Geochem. 23 (2008) 955. 


\section{Figure captions}

Fig. 1. Adsorption isotherms for the anions onto HT. Equilibrium pH ranged from 10.7 to 11.1 in the $\mathrm{NO}_{3}$ system, from 10.8 to 10.9 in the $\mathrm{Cl}$ system, from 10.8 to 11.4 in the $\mathrm{SO}_{4}$ system, from 10.7 to 11.3 in the $\mathrm{AsO}_{4}$ system, and from 10.6 to 11.4 in the $\mathrm{PO}_{4}$ system. The concentrations of solids were adjusted to $1.0 \mathrm{~g} / \mathrm{L}$. Each plot indicates the average of two different samples.

Fig. 2. XRD patterns of rehydrated HT and HT with different anions. The initial anion concentration was adjusted to $10 \mathrm{mmol} / \mathrm{L}$ for each sample.

Fig. 3. Zeta potentials of HT with the different anions. The equilibrium $\mathrm{pH}$ of rehydrated HT suspension was 10.6. The equilibrium $\mathrm{pH}$ ranged from 10.7 to 11.1 in the $\mathrm{NO}_{3}$ system, from 10.8 to 10.9 in the $\mathrm{Cl}$ system, from 10.8 to 11.4 in the $\mathrm{SO}_{4}$ system, from 10.7 to 11.3 in the $\mathrm{AsO}_{4}$ system, and from 10.6 to 11.4 in the $\mathrm{PO}_{4}$ system.

Fig. 4. (A) ATR-FTIR spectra of $\mathrm{SO}_{4}$ : (a) the $0.5 \mathrm{~mol} / \mathrm{L} \mathrm{Na}_{2} \mathrm{SO}_{4}$ solution adjusted to $\mathrm{pH} 10$, and (b) HT-SO 4 with 0.865 mmol-SO $4 /$ g-calcined HT. (B) ATR-FTIR spectra of $\mathrm{AsO}_{4}$ : (a) the 0.5 mol/L $\mathrm{Na}_{2} \mathrm{HAsO}_{4}$ solution adjusted to $\mathrm{pH}$ 10, and (b) $\mathrm{HT}_{-}-\mathrm{AsO}_{4}$ with 1.91 mmol-AsO $/$ g-calcined HT. (C) ATR-FTIR spectra of $\mathrm{PO}_{4}$ : (a) the $0.5 \mathrm{~mol} / \mathrm{L} \mathrm{Na}_{2} \mathrm{HPO}_{4}$ solution

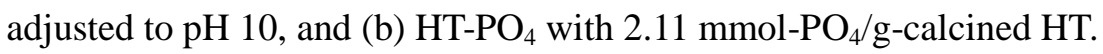

Fig. 5. Changes in the zeta potential of rehydrated HT and HT with the different anions as a function of $\mathrm{pH}$. The initial anion concentration was adjusted to $10 \mathrm{mmol} / \mathrm{L}$ for each sample. The 
concentrations of suspended solids were adjusted to $1.0 \mathrm{~g} / \mathrm{L}$, and a $\mathrm{pH}$ was changed by adding $0.1 \mathrm{~mol} / \mathrm{L} \mathrm{HNO}_{3}$ solution.

Fig. 6. $\mathrm{IAP}_{\mathrm{HT}}$ in the reacted solutions as a function of the amount of adsorbed anions. 


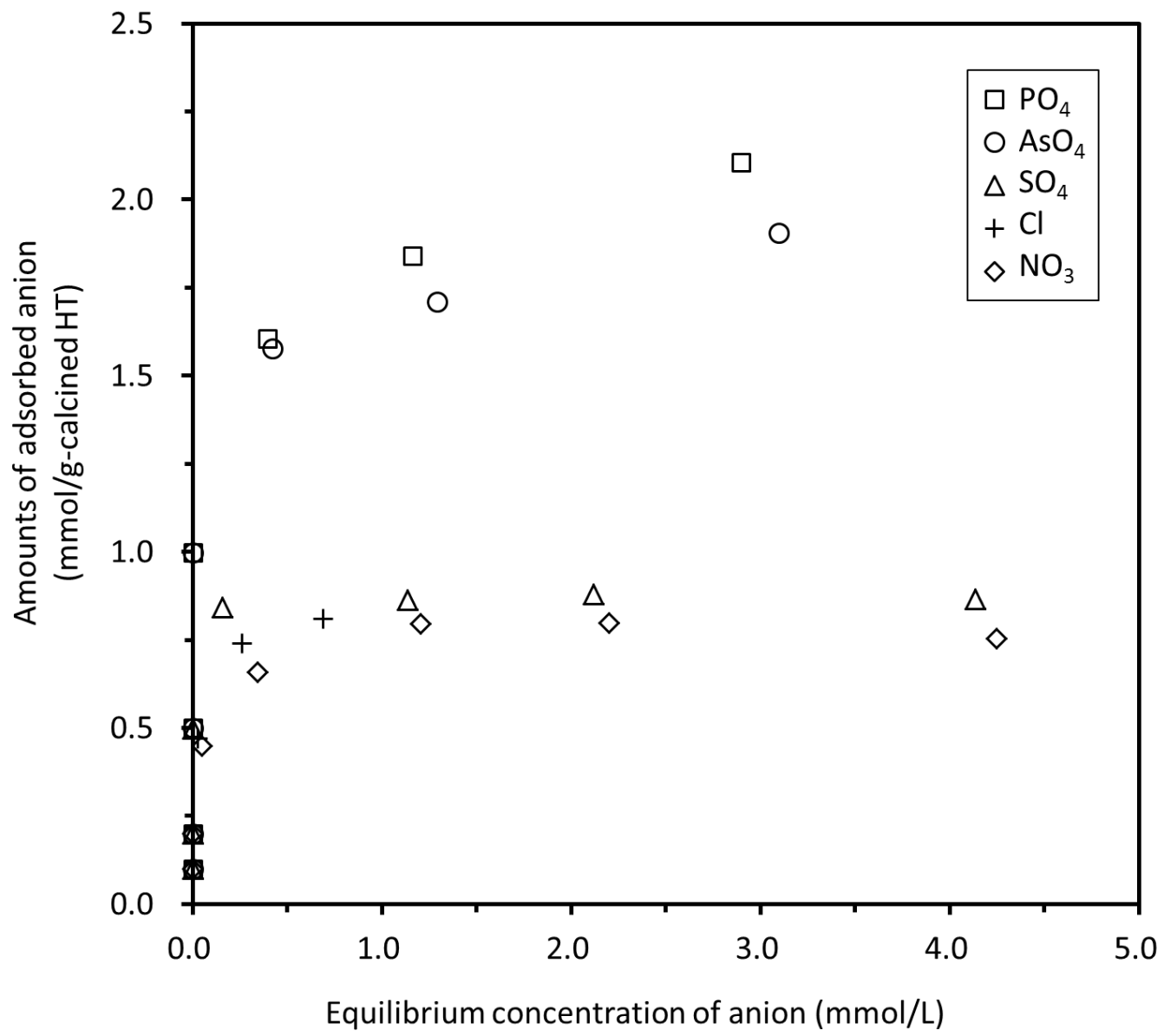

Fig. 1. Adsorption isotherms for the anions onto HT. Equilibrium $\mathrm{pH}$ ranged from 10.7 to 11.1 in the $\mathrm{NO}_{3}$ system, from 10.8 to 10.9 in the $\mathrm{Cl}$ system, from 10.8 to 11.4 in the $\mathrm{SO}_{4}$ system, from 10.7 to 11.3 in the $\mathrm{AsO}_{4}$ system, and from 10.6 to 11.4 in the $\mathrm{PO}_{4}$ system. The concentrations of solids were adjusted to $1.0 \mathrm{~g} / \mathrm{L}$. Each plot indicates the average of two different samples. 


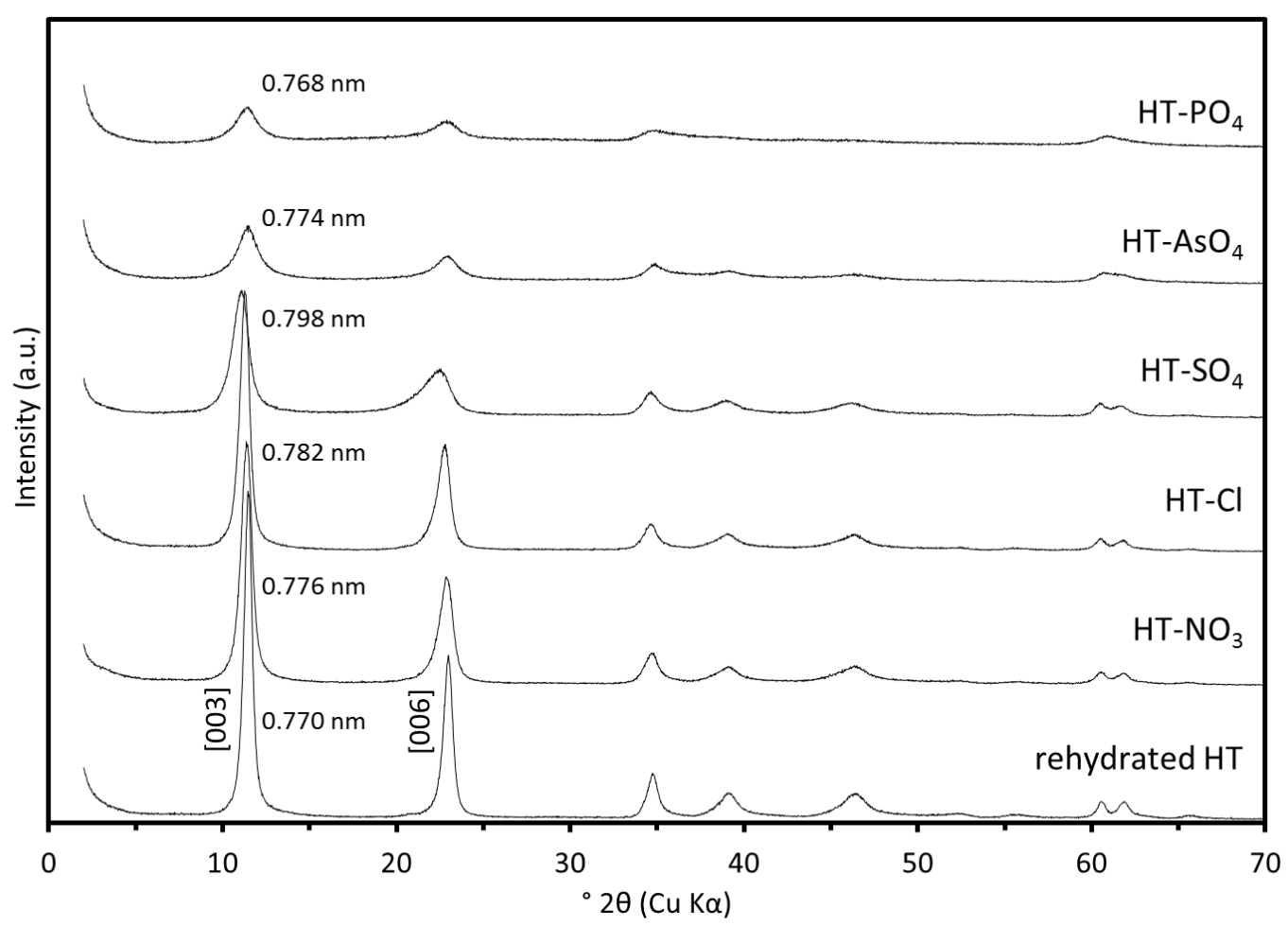

Fig. 2. XRD patterns of rehydrated HT and HT with different anions. The initial anion concentration was adjusted to $10 \mathrm{mmol} / \mathrm{L}$ for each sample. 


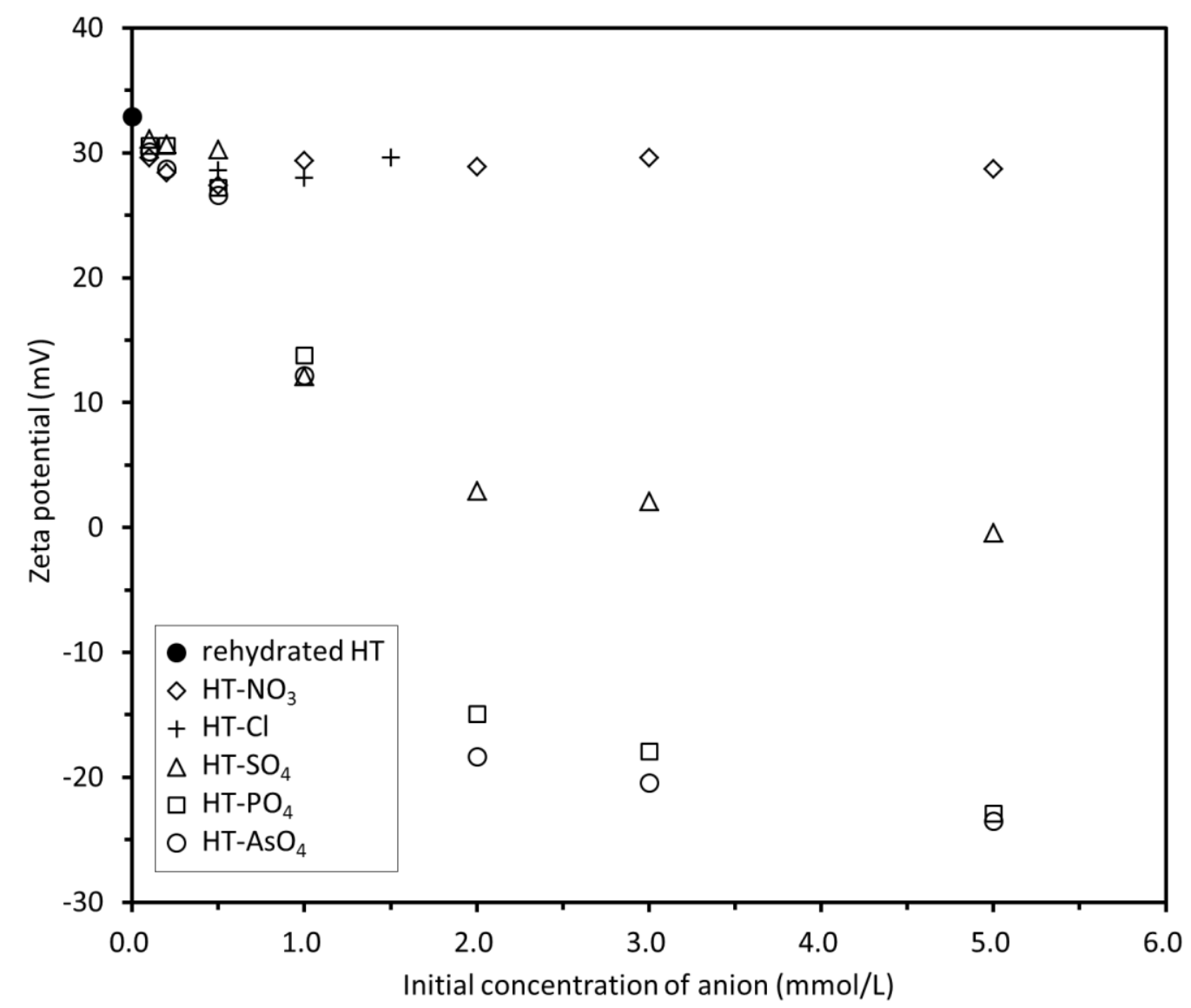

Fig. 3. Zeta potentials of HT with the different anions. The equilibrium $\mathrm{pH}$ of rehydrated HT suspension was 10.6. The equilibrium $\mathrm{pH}$ ranged from 10.7 to 11.1 in the $\mathrm{NO}_{3}$ system, from 10.8 to 10.9 in the $\mathrm{Cl}$ system, from 10.8 to 11.4 in the $\mathrm{SO}_{4}$ system, from 10.7 to 11.3 in the $\mathrm{AsO}_{4}$ system, and from 10.6 to 11.4 in the $\mathrm{PO}_{4}$ system. 

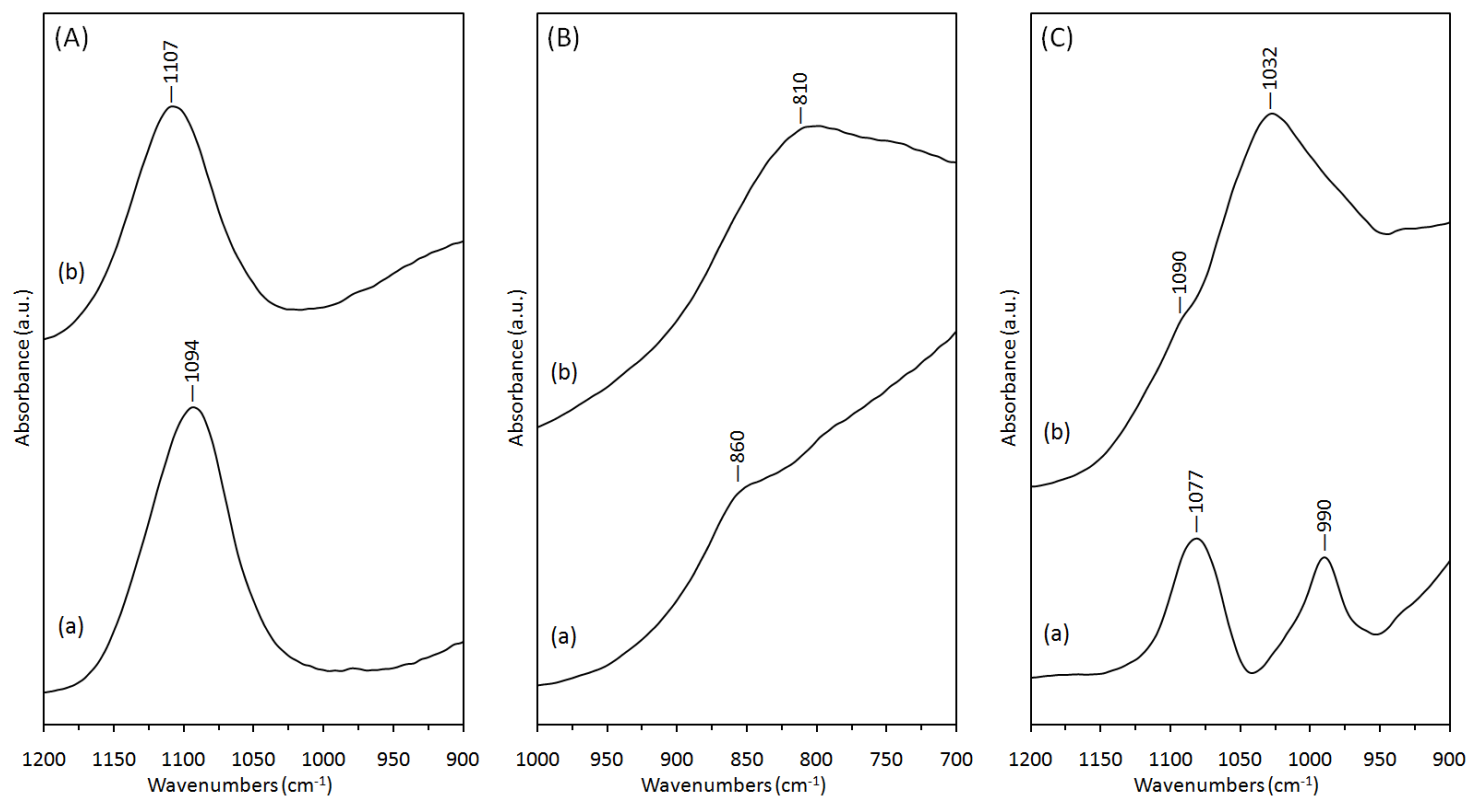

Fig. 4. (A) ATR-FTIR spectra of $\mathrm{SO}_{4}$ : (a) the $0.5 \mathrm{~mol} / \mathrm{L} \mathrm{Na}_{2} \mathrm{SO}_{4}$ solution adjusted to $\mathrm{pH} 10$, and

(b) $\mathrm{HT}-\mathrm{SO}_{4}$ with 0.865 mmol-SO $4 /$-calcined HT. (B) ATR-FTIR spectra of $\mathrm{AsO}_{4}$ : (a) the 0.5 $\mathrm{mol} / \mathrm{L} \quad \mathrm{Na}_{2} \mathrm{HAsO}_{4}$ solution adjusted to $\mathrm{pH} \quad 10$, and (b) $\mathrm{HT}^{-\mathrm{AsO}_{4}}$ with 1.91 mmol-AsO $/$ g-calcined HT. (C) ATR-FTIR spectra of $\mathrm{PO}_{4}$ : (a) the $0.5 \mathrm{~mol} / \mathrm{L} \mathrm{Na}_{2} \mathrm{HPO}_{4}$ solution adjusted to $\mathrm{pH}$ 10, and (b) $\mathrm{HT}-\mathrm{PO}_{4}$ with $2.11 \mathrm{mmol}-\mathrm{PO}_{4} / \mathrm{g}$-calcined HT. 


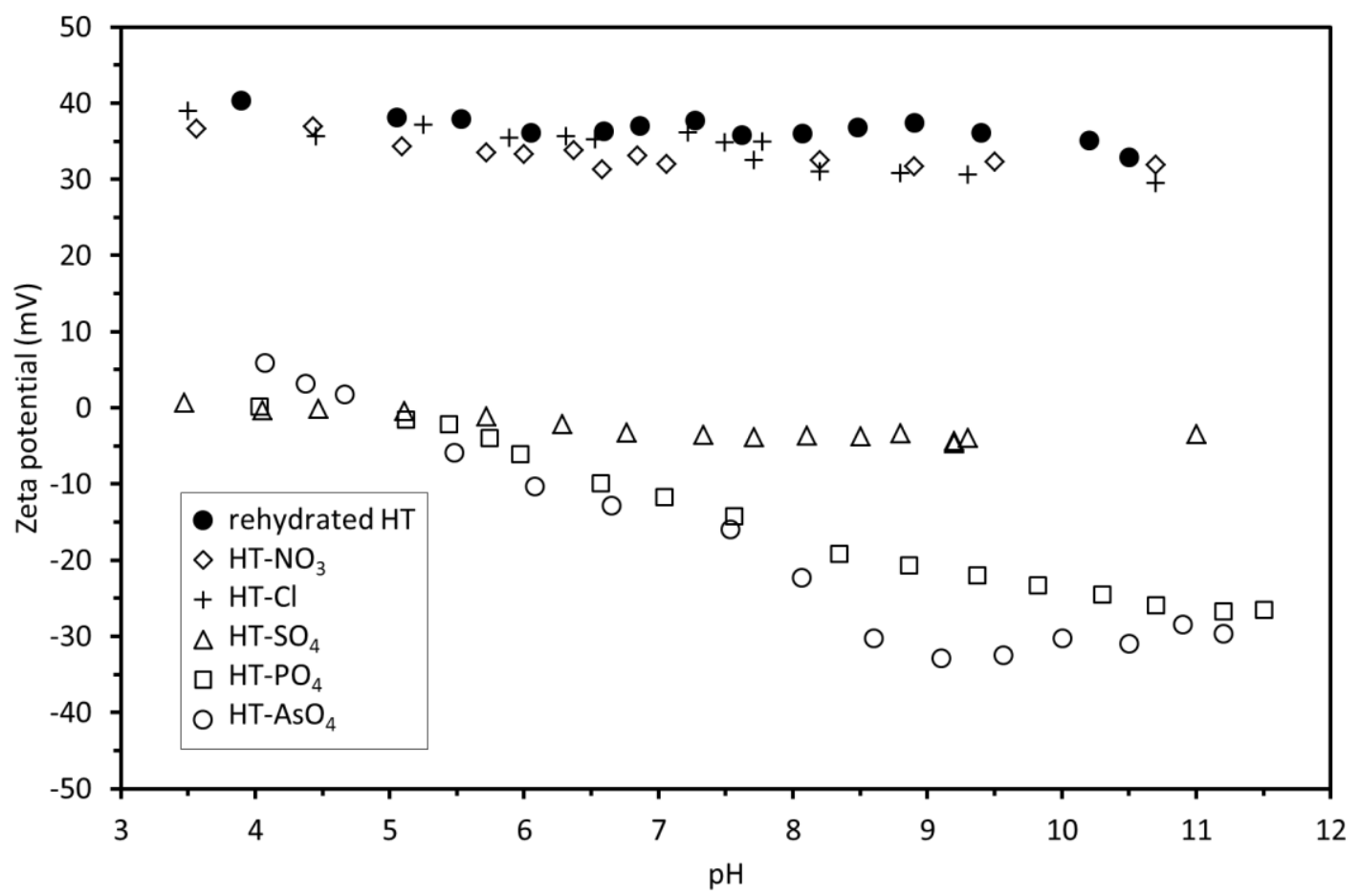

Fig. 5. Changes in the zeta potential of rehydrated HT and HT with the different anions as a function of $\mathrm{pH}$. The initial anion concentration was adjusted to $10 \mathrm{mmol} / \mathrm{L}$ for each sample. The concentrations of suspended solids were adjusted to $1.0 \mathrm{~g} / \mathrm{L}$, and a $\mathrm{pH}$ was changed by adding $0.1 \mathrm{~mol} / \mathrm{L} \mathrm{HNO}_{3}$ solution. 


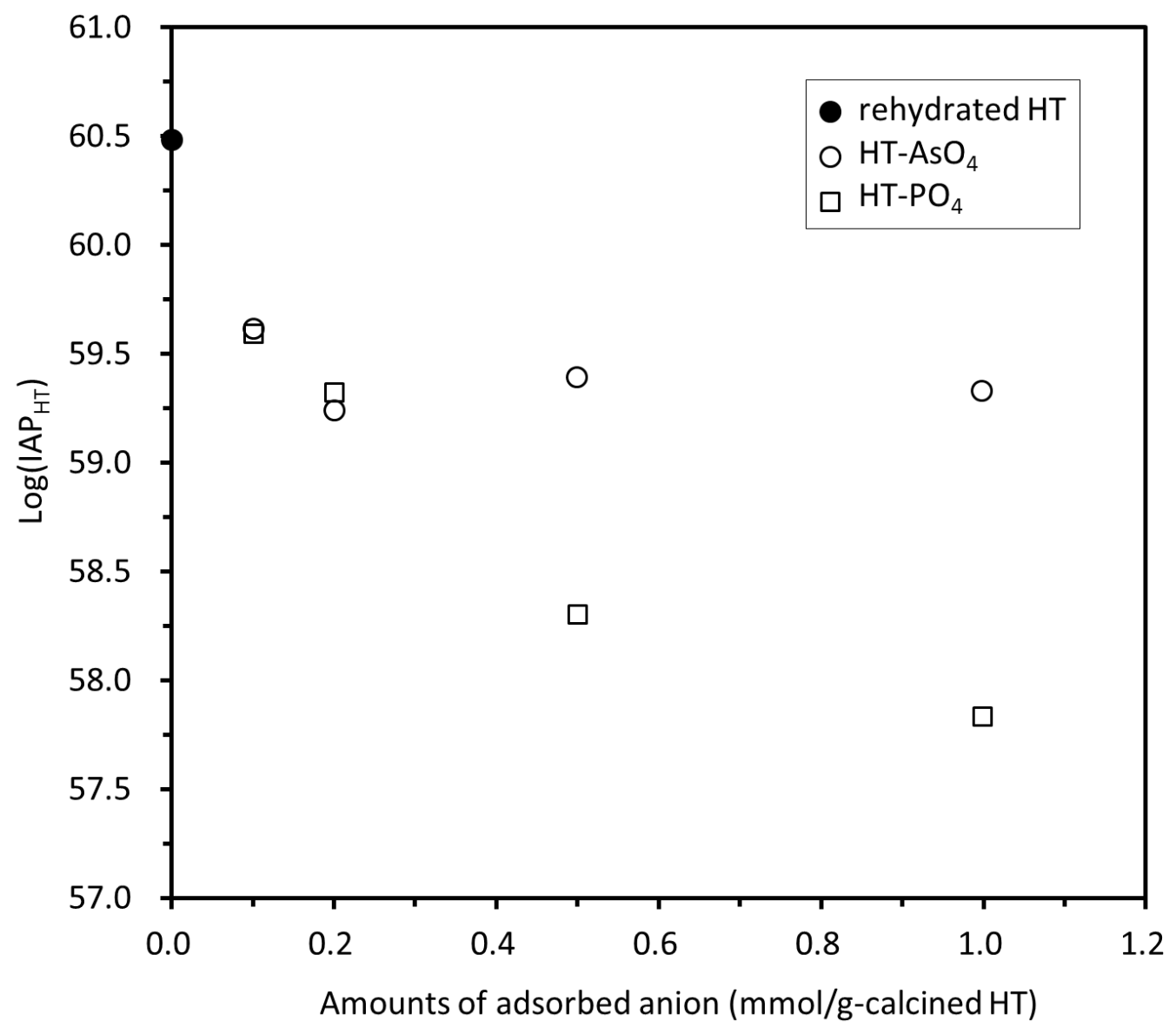

Fig. 6. $\mathrm{IAP}_{\mathrm{HT}}$ in the reacted solutions as a function of the amount of adsorbed anions. 